\title{
Vesicouterine fistula - a rare delayed complication of cesarean section
}

\author{
S AKTER ${ }^{\mathrm{a}}, \mathrm{K}^{\mathrm{BEGUM}}{ }^{\mathrm{b}}, \mathrm{J} \mathrm{SAHA}^{\mathrm{c}}$
}

\begin{abstract}
:
A vesicouterine fistula is an abnormal pathway between the urinary bladder and the uterus. It is a rare urogynaecological fistula. In vesicouterine fistula, clinical presentations are cyclic haematuria (menouria), amenorrhoea, urinary continence which mimics Youssef's syndrome. This case presents, a 37 year old multiparous woman with vesicouterine fistula which she developed 8 years after cesarean
\end{abstract}

\section{Introduction:}

Vesicouterine fistula is a rare form of urogynaecological fistula when compared with vesicovaginal fistula. It represents about $1-4 \%$ of all cases of urogynaecological fistula ${ }^{1}$. About $83-93 \%$ of cases, it is usually iatrogenic following cesarean section ${ }^{2,3,4}$. Other causes of fistula may be due to following induced abortion, obstructed labour, instrumental delivery, vaginal birth after cesarean section, placenta percreta, brachytherapy, migrated intra uterine contraceptive devices ${ }^{5}$. Less frequent causes are inflammatory bowel disease, endometriosis and bladder tuberculosis ${ }^{6,7}$. Vesicouterine fistula was first reported in the literature in 1908 by knipe ${ }^{8}$. It was described by Youssef in 1957 as a clinical syndrome consisting of cyclic haematuria (menouria), amenorrhoea, and complete urinary incontinence in a patient who had lower segment cesarean section'. A suggested classification of VUF, based on the routes of menstrual flow proposed by Józwik and Józwik ${ }^{10}$ in 2000, divides vesicouterine fistula (VUF) into three types. Type 1 is characterized by the triad of amenorrhoea and menouria and the complete continence of urine

\footnotetext{
a. Dr. Sumaya Akter, Assistant Professor. OBGYN

b. Prof. Kohinoor Begum, Professor, OBGYN

c. Dr. Joysree Saha, Associate Professor, OBGYN
}

Adddress of Correspondence: Dr. Sumaya Akter, Affiliation : Assistant Professor, OBGYN, Popular Medical College, Postal Address: House \#25, road\#2, Dhanmondi-1205, Phone No: 01711231534, Email : sumaya.akter@yahoo.com section. Diagnosis was confirmed by cystoscopy and fistula was repaired through trans abdominal surgery. She regained normal vaginal menses 4 months after surgery.

Keywords: vesicouterine fistula, delayed complication, Youssef's syndrome, cystoscopy.

(J Bangladesh Coll Phys Surg 2020; 38: 209-212)

DOI: https://doi.org/10.3329/jbcps.v38i4.48984

has been known as Youssef's syndrome; Type ii is associated with dual menstrual flow via both the bladder and vagina and type iii is associated with normal menses and lack of menouria ${ }^{10}$. Usually, immediate presentation occurs when there is direct injury to the bladder during surgery. Patients can have early hematuria and/or urinary leakage, voiding difficulty, low-grade pyrexia, urinary sepsis or be completely asymptomatic ${ }^{7}$. Delayed presentation can occur when there is an infection or a progressive devitalization of the posterior wall of the bladder ${ }^{11}$. Patients with delayed presentation often have symptoms of urinary leakage from the vagina if the cervix is incompetent, cyclic hematuria (menouria), amenorrhea, infertility or first trimester abortion ${ }^{11}$. Most of the cases present in delayed fashion, from weeks to years after the inciting event ${ }^{12}$. In such cases diagnosis can be done by detection of urine colour after dye passing through cervical external os or by HSG or cystoscopy. Conservative treatment may be approachable but surgery is the best option. We report a case of successful surgical repair of VUF which was developed after many years of cesarean section.

\section{Case report:}

Mrs "X", 37 year old multipara came to our clinic with complaints of passage of bloody urine during menstruation for 2 episodes following 3 months of amenorrhoea. She had H/O repeat cesarean section 8 years back. There was no post operative complication after surgery. She had no history of induced abortion or any other surgery in uterus after last LUCS. She 
did not complain of dysuria or lower abdominal pain. She also did not give any history of urinary incontinence. Then she was given progesterone to stop menstruation for 2 months. At that time there was no per vaginal bleeding or passage of bloody urine. USG showed normal uterine and ovarian structure, no stone in urinary bladder. Urine routine microscopic examination revealed normal.

AFB was not found in endometrial tissue. Then cystoscopic evaluation was done. Trigone was normal. There was a small opening about $1 \mathrm{~mm}$ in supratrigone region of bladder. No feature of granuloma was found.

Methylene blue dye was pushed through cervix and it passed through the bladder opening. Then decision of laparotomy was taken. After opening the abdomen bladder was found adherent with anterior uterine wall. About $1 \mathrm{~mm}$ of opening was found in body of uterus which communicated with base of bladder. Fistula was repaired. Catheter was kept in bladder for 21 days. Progesterone was given for 1 month to induce amenorrhoea. Urine colour was normal. Her menstruation started 4 months after surgery. She also relieved of haematuria after surgery.

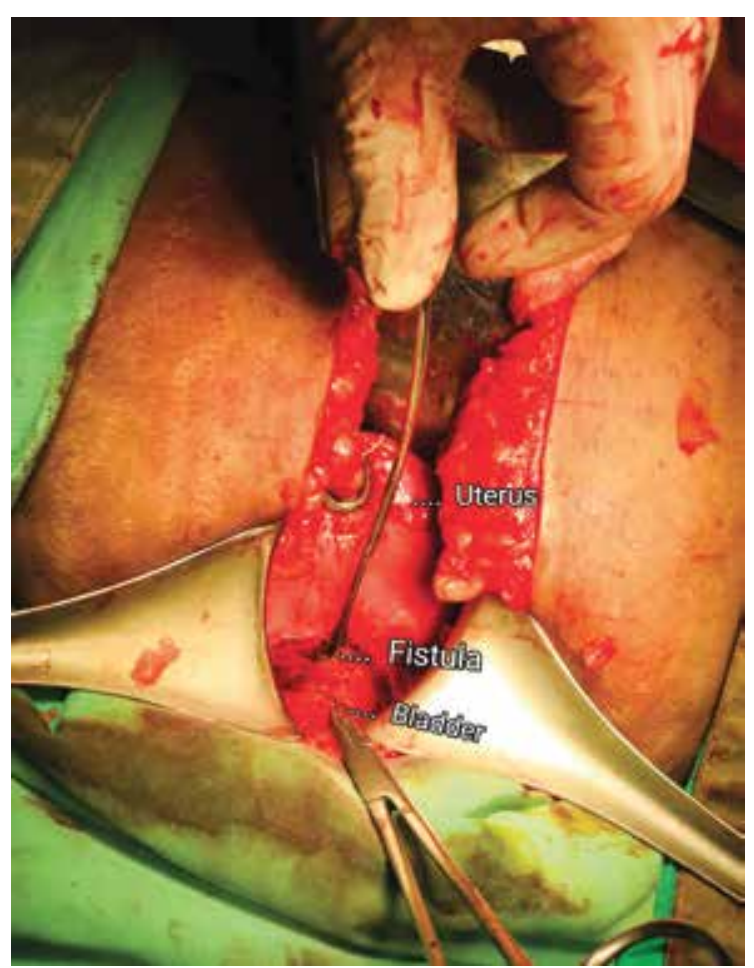

Figure 1 - fistula between bladder base and uterus

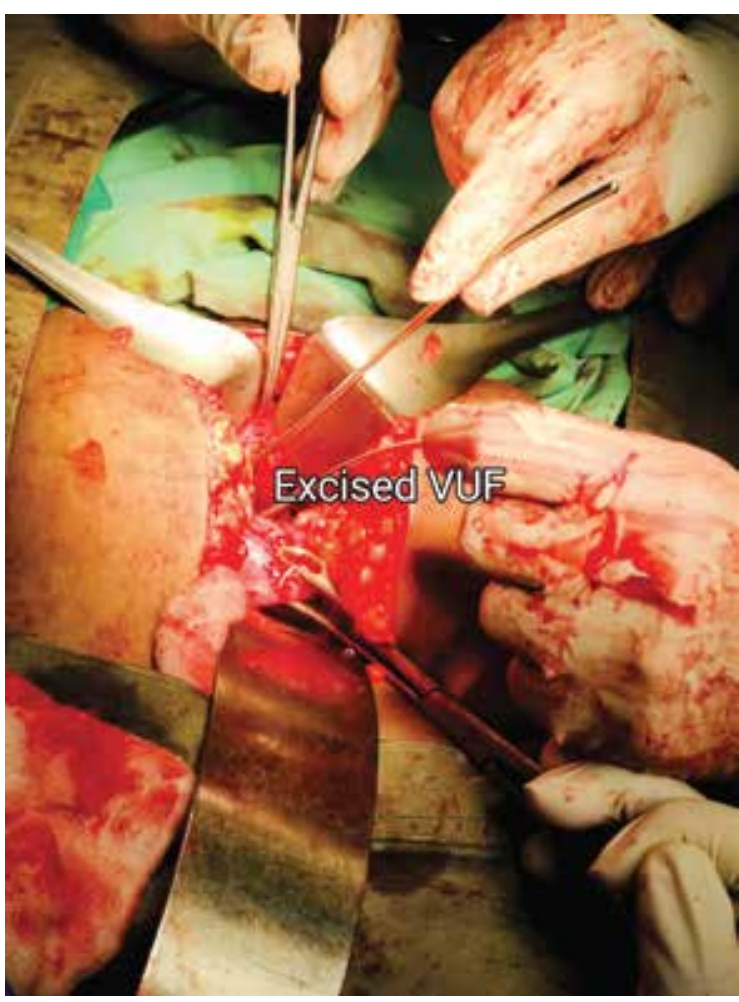

Figure 2- after excision of vesicouterine fistula (VUF) Discussion :

The world health organization estimates 130,000 new cases of urogenital fistula occuring per year. Vesicouterine fistula represents only $2-9 \%$ of all urogenital

fistula $a^{13,14}$. The frequency of vesicouterine fistulae in relation to other urogenital fistula, as previously reported, varies from $1 \%$ to $16.4 \%{ }^{15}, 16$. It is very likely that there is an increase in the relative frequency of this type of fistula, because of the increase in cesarean section rates. Typically patient presents with cyclic haematuria or menouria, amenorrhoea and urinary continence, as described in Yossef's syndrome ${ }^{9}$. Our patient presented with these classical clinical features. Other presenting complaints can include perineal irritation, vaginal fungal infection, and recurrent urinary tract infections ${ }^{17}$.

Previously she had two lower segment cesarean section which is one of the important iatrogenic cause of vesicouterine fistula ${ }^{9}$. Probable factors which may lead to formation of vesicouterine fistula after LUCS are as follows - a) an inadequate reflection of the bladder from the lower uterine segment during cesarean section is the main cause of injury of the 
bladder either during uterotomy or uterine closure. b) Inadequate downward mobilization of bladder or direct injury to that portion of the bladder which sometimes adherent to the anterior vaginal wall or lower segment wall ${ }^{5}, \mathrm{c}$ ) aberrant sutures placed so that a knuckle of bladder is caught in the sutures ${ }^{5}$. Repeated Cesarean sections may result in progressive devitalization and scarring of the uterus and bladder base by damaging their vascular network, thus predisposing to delayed fistula formation ${ }^{11}$. But to develop vesicouterine fistula after 8 years of LUCS is most unlikely and rare. Her endometrial tissue and fistula margin was send for histopathology but no granulomatous lesion was found. AFB stain was also negative.

If the diagnosis of VUF is early and the fistula presumed to be small, conservative measures with prolonged catheterization with antibiotics and anticholinergic for about 4 weeks have been reported to be effective and provides a cure rate in about $5 \%$ of cases ${ }^{12,18,19}$. Our patient had developed VUF , 8 years after lower uterine cesarean section. Diagnosis was made from history, clinical feature of Type 1 Youssef's syndrome ${ }^{9}$ and confirmed by cystoscopy which showed about $1 \mathrm{~mm}$ of fistula in supratrigone region of urinary bladder and dye test was positive. Other imaging procedure can be useful to fully characterize the fistulous tract. But there is no clear consensus on the best modality ${ }^{20}$. Cystography, hysterography, excretory urography, also ultrasonography with or without intra uterine saline infusion ${ }^{21,22}$ can complete the diagnostic workup. MRI has now become the first choice in the investigation of fistulas ${ }^{23,24}$.

The definitive treatment for Youssef's syndrome is surgical. Conservative measure such as prolonged catheterization 18,19 and medical management to cause induced amenorrhoea to help fistula healing with oral contraceptive, progesterone and GnRH analog have been reported in the literature with successful outcomes ${ }^{25,26}$.

Surgery can be performed transabdominally, endoscopically or robotically. Transvaginal approach is less favored because of higher location of the fistula and its complexity ${ }^{16}$.

Hysterectomy is not indicated for this treatment ${ }^{27}$. Disadvantage of the trans abdominal route are increased morbidity, long hospital stay and increased blood loss. These can be overcome by using endoscopic and robotic approach ${ }^{28}$.
In our case the supratrigonal vesicouterine fistula was repaired through intraperitonial approach. In bladder, fistula opening was closed in two layers after mobilization of uterine wall from bladder by dissection and uterine opening was repaired in single layer suture. There was no menouria after repair and menses was commenced normally.

After correction of VUF, successful pregnancy outcome was also reported.

\section{Conclusion:}

Vesicouterine fistula is a rare variety of genitourinary fistula. Previously it was occurred after complicated vaginal delivery. Due to increasing trend of lower segment cesarean section, incidence of VUF also rise. So surgeons should be more careful during cesarean section to avoid complication. Patient must be councelled about the consequence of repeat cesarean section.

\section{References:}

1. Iloabachie GC, Njoku O. Vesicouterine fistula. BRITISH J Urol 1985;57:438-9. https://doi.org/10.1111/ j.1464-410X. 1985.tb06305.x, PMid:4027516

2. Eisenkop SM, Richman R, Platt LD, Paul RH. Urinary tract injury during cesarean section. Obst Gynecol 1982;60:591-6

3. Buchholz NP, Daly- Grandeau E, Huber - buccholz MM. Urological complications associated with caesarean section. Eur J obstet gynecol Biol 1994:56:161-3. https://doi.org/10.1016/0028-2243(94)90163-5

4. Yossepwitch O, Baniel J, Livne PM. Urological injuries during cesarean section: Intraoperative diagnosis and management. J Urol 2004;172:196-9. https://doi.org/ 10.1097/01.ju.0000128632.29421.87, PMid:15201771

5. Tancer ML. Vesico uterine fistula- a review. Obstet gynaecol Surv 1986;41:743-53. https://doi.org/10.1097/ 00006254-198612000-00001, PMid:3540759

6. DiMarco CS, DiMarco DS, Klingel CL, Gebhart JB. Vesicouterine fistula: A review of eight cases. Int Urogynecol j Pelvic Floor Dysfunct 2006; 17:395-9., https://doi.org/10.1007/s00192-005-0025-2, PMid:16523247

7. Alkatib M, Franco AV, Fynes MM. Vesiciuterine fistula following cesarean delivery-ultrasound diagnosis and surgical management. Ultrasound Obstet Gynecol 2005; 26:183-5. https://doi.org/10.1002/uog.1925, PMid:15997459

8. Knipe WHW. Vesico-uterine fistula Am J Obstet Gynecol. 1908;57:211-7.

9. Youssef AF. Menouria following lower segment cesarean section: a syndrome. Am J Obstet Gynecol. 1957;73:759-67 
10. józwik $M$ józwik $M$. clinical classification of vesicouterine fistula. Int j gynecol Obst. 2000;70:353-7. https://doi.org/10.1016/S0020-7292(00)00247-2

11. Porcaro AB, Zicari M, Zecchini Antniolli S, Pianon R, Monaco C, Migliorini F, et al. Vesicouterine fistulas following cesarean section: report on a case, review and update of the literature. Int urol Nephrol (2002) 34:335-44. https://doi.org/10.1023/A:1024443822378, PMid:12899224

12. B.K. Park, S. H. Kim, J.Y. Cho, J.S.Sim and C.K. Seong, "Vesicouterine fistula after cesarean section: ultrasonographic findings in two cases," Journal of Ultrasound in Medicine, vol.18, no. 6, pp. 441443,1999. https://doi.org/10.7863/jum.1999.18.6.441, PMid:10361852

13. Hadzi- Djokic JB, Pejcic TP, Colovic VC. Vesico-uterine fistula: Report of 14 cases. BJU int 2007;100:1361-3. https://doi.org/10.1111/j.1464-410X.2007.07067.x, PMid:17590179

14. El- Lamie I. urogenital fistulae: changing trends and personal experience of 46 cases. Int urogynecol j Pelvic floor Dysfunct (2008) 19:26772. https://doi.org/ 10.1007/s00192-007-0426-5, PMid:17639345

15. Józwik M, Józwik M, LotockiW. Vesicouterine fistula-an analysis of 24 cases from Poland. Int J Gynaecol Obstet 1997;57(02): 169-172. https://doi.org/10.1016/ S0020-7292 (97)02837-3

16. Yip SK, Leung TY. Vesicouterine fistula: an updated review. Int urogynecol j pelvic Floor Dysfunct 1998;9:252-6. https://doi.org/10.1007/BF01901500, PMid:9849756

17. Park OR, kim TS, Kim HJ. Sonographic diagnosis of vesicouterine fistula . Ultrasound Obstet Gynecol (2003) 22:82-4. https://doi.org/10.1002/uog.161, PMid:12858310

18. Kilinc F, Bagis T, Guvel S, Egilmez T, ozkardes H. Unusual case of post- cesarean vesicputerine fistula (Youssef's syndrome) int J Urol 2003; 10:236-8., https://doi.org/10.1046/j.0919-8172.2003.00599.x, PMid:12657106

19. Bastakoti R, Saha R. Congervative management of uterovesical fistula following primary cesarean section. JKMC 2014: 2:211-3. https://doi.org/10.3126/jkmc.v2i4.11799
20. Moon SG, kim SH, Lee HJ, Moon MH, Myung JS. Pelvic fistulas complicating pelvic surgery or diseases: spectrum of imaging findings. Korean $\mathrm{J}$ radiol (2001)2:97-104. https://doi.org/10.3348/kjr.2001.2.2.97, PMid:11752977 PMCid:PMC2718108

21. Ali-El-Dein, El- Tabey N, El- Hefnawy A, Osman Y, Soliman S, Shaaban AA, Diagnosis, treatment and need for hysterectomy in management of post cesarean section vesico uterine fistula. Scand J Urol (2014) 48:460-5., https://doi.org/10.3109/21681805.2014.903511, PMid:24694181

22. Tancer ML. Observation on prevention and management of vesicovaginal fistula after total hysterectomy. Surg Gynecol Obstet (1992) 175:501-6.

23. P. Narayanan, M. Nobbenhuis, K. M. Reynolds, A. Sahdeb, R. H. Reznek, and A.G. Rockall, " fistulous in malignant gynecologic disease; etiology, imaging and management," Radiographics, (2009) vol. 29;4:107383. https://doi.org/10.1148/rg.294085223 PMid:19605657

24. G. L. Brodhead . Spontaneous closure of large vesico-uterine fistula, Medication reconciliation. (1920);98:437.

25. Rubino SM. Medical treatment of utero- vesical fistula. Lancet 1977;309:900-0. https://doi.org/10.1016/ S0140-6736 (77)91218-1

26. Birge O, Ozbey EG, Erkam MM, Arslan D, Kayar i. Youssef's syndrome following cesarean section. Case reports. Obstet Gynecol 2015;2015:1- https://doi.org/ 10.1155/2015/605325, PMid:26457214, PMCid:PMC4589585

27. Bettez M, Breault G, Carr L, Tu Lm. Early versus delayed of vesicouterine fistula. J Can urol Assoc 2011; 5(4):457-9. https://doi.org/10.5489/cuaj.10065, PMid:21806894 PMCid:PMC3148396

28. K. Parveen, R. Gupta, Al=Badr and A.K. Hemal. Robot assisted laparoscopic repair of rare post-cesarean section vesicocervical and vesicouterine fistula: a case series of a novel technique. Urology (2012) 80:477-82. https://doi.org/ 10.1016/j.urology.2012.04.027, PMid:22705111 